\title{
Seeking SDG indicators
}

To the Editor - The official global indicators intended to measure progress toward the Sustainable Development Goals (SDGs) were adopted by the United Nations in $2017^{1}$. This comprehensive list of indicators was prepared by the Inter-agency and Expert Group on SDG Indicators, which was created by the United Nations Statistical Commission in 2015. It is therefore reasonable to expect that by now we would be using reliable and timely information obtained through those indicators. Unfortunately, this is not the case.

The SDG indicators are classified into three tiers based on their methodological matureness and the availability of data. Internationally established methodologies or standards are still lacking for $17 \%$ of the 232 indicators, as shown by the number of so-called Tier III indicators. Furthermore, there are also serious problems with data availability for those indicators with a sound methodological basis.

The time for development of further indicators is running short. According to official descriptions of the targets, 21 of the 169 targets behind the 17 SDGs should have already been reached by 2020. Despite the fact that the SDGs should officially be met by 2030 , in many cases the current pace means that the target year will pass before the official global indicator is ready for use.

The situation is also worrying at the national level. Nationally based custodian agencies are expected to deliver the data for the indicators. Finland was one of the first countries to collect the data and publish national SDG indicators. However, the Finnish set of SDG indicators released in February 2019 showed that national data were missing for nearly half (47\%) of the global indicators. Countries with less-developed statistical systems and data-collection mechanisms face even greater challenges.

The role of the official global SDG indicators in monitoring, reporting and assessment should be critically reconsidered in order to avoid unnecessary delays in the policy actions needed to reach the sustainability goals. Ideally, indicators should simplify the complex framework of the 17 SDGs and 169 targets and pinpoint the most crucial gaps in implementation.

Perhaps the most obvious problem with the current approach is that key indicators describing progress towards the 17 SDGs are lacking. Both the policy relevance of indicators and the practical manageability of indicator production could be improved by concentrating on a limited set of key indicators selected from the current list of SDG indicators or from other information sources. The use of the existing indicators and the knowledge needs of decisionmaking processes should also be analysed and addressed.

Alternative approaches for monitoring international activities and providing a basis for cross-national comparisons include more focused sets of indicators, such as the SDG Index and Dashboard Reports ${ }^{2}$, or utilization of novel indicators, for instance the indicators based on remote sensing ${ }^{3}$. Waiting for a complete set of official SDG indicators is no longer a viable option.

\section{Jari Lyytimäki}

Finnish Environment Institute, Helsinki, Finland. e-mail: jari.lyytimaki@ymparisto.fi

Published online: 8 July 2019

https://doi.org/10.1038/s41893-019-0346-7

\footnotetext{
References

1. Resolution Adopted by the General Assembly on 6 July 2017 A/RES/71/313 (United Nations, 2017); https://undocs.org/ A/RES/71/313

2. Nat. Sustain. 1, 377 (2018)

3. Andries, A. et al. Sustain. Dev. 27, 366-376 (2019).
} 